\title{
Autoscopia: um procedimento de pesquisa e de formação
}

\author{
Ana Maria Falcão de Aragão Sadalla \\ Universidade Estadual de Campinas \\ Priscila Larocca \\ Universidade Estadual de Ponta Grossa
}

\section{Resumo}

Este artigo trata de um procedimento de coleta de dados denominado autoscopia. A autoscopia vale-se do recurso de videogravação de uma prática, visando a análise e auto-avaliação por um ou mais protagonistas dessa prática. Por meio da videogravação objetiva-se apreender as ações do ator (ou atores), o cenário e a trama que compõem uma situação. 0 material videogravado é submetido a sessões de análise a posteriori da ação os quais se destinam a apreensão do processo reflexivo do ator (ou atores), através de suas verbalizações durante a análise das cenas videogravadas. 0 artigo apresenta uma fundamentação teórica do procedimento de autoscopia, aborda vantagens e limites de sua utilização, bem como os cuidados a serem considerados e, finalmente, descreve as experiências das autoras em duas pesquisas em que o procedimento foi utilizado. A partir de duas experiências, apontam-se diferenças e semelhanças entre os trabalhos, especialmente relacionados aos participantes, objeto e à distribuição no tempo das videogravações. As autoras tecem considerações sobre o potencial formativo-reflexivo do procedimento, tanto em situações de pesquisa como de aprendizagem e formação de diferentes profissionais, considerando ser este um excelente instrumento de formação. No entanto, é vital que se tenha em mente a necessidade de reconhecer e devolver ao professor, enquanto partícipe autoscópico, a condição de sujeito de sua própria profissão, promovendo, portanto, além da avaliação de si, também a autonomia do seu pensar e fazer.

\section{Palavras-chave}

Metodologia de pesquisa - Autoscopia - Formação profissional Formação reflexiva. 


\title{
Autoscopy: a procedure of research and education
}

\author{
Ana Maria Falcão de Aragão Sadalla \\ Universidade Estadual de Campinas \\ Priscila Larocca \\ Universidade Estadual de Ponta Grossa
}

\begin{abstract}
This article considers a procedure for data collection called autoscopy. Autoscopy entails the video recording of a practice with the purpose of allowing analysis and self-evaluation by one of the protagonists of that practice. The objective of the video recording is that of apprehending the actions of the agent (or agents), the scenario, and the plot that make up a situation. The recorded material is subjected to sessions of analysis after the action that aim at the understanding of the reflective process of the agent (or agents) through their verbalizations during the analysis of video recorded scenes. The present text introduces a theoretical basis for the procedure of autoscopy, deals with advantages and limitations of its use, as well as with aspects that deserve attention and, finally, describes the authors' experiences in two studies in which the procedure was employed. Starting from these two experiences, differences and similarities are pointed out between the studies, especially regarding the participants, object, and the time distribution of the video recordings. The authors draw considerations about the formativereflective potential of the procedure, both for research situations and for the learning and training of various professionals, considering it to be an excellent educational instrument. It is, however, vital to keep in mind the need to recognize and return to the teacher, as an autoscopic participant, his condition as subject of his own profession, thereby promoting, besides the self-evaluation, also the autonomy of his thinking and doing.
\end{abstract}

\section{Keywords}

Research methodology - Autoscopy - Professional training Reflective education.

Contact:

Ana Maria F. de Aragão Sadalla

Rua Eng Alexandre A. Cavaleri,

160 - casa 2

13101-518 - Campinas - SP

e-mail: anaragao@terra.com.br 
A palavra "autoscopia” é composta pelos termos "auto" e "scopia". 0 primeiro trata de uma ação realizada pelo próprio sujeito e o segundo refere-se a escopo (do grego skoppós e latim scopu), que quer dizer objetivo, finalidade, meta, alvo ou mira. A idéia de autoscopia diz respeito, portanto, a uma ação de objetivar-se, na qual o $\mathrm{e} u$ se analisa em torno de uma finalidade.

Neste artigo, a autoscopia é tratada como técnica de pesquisa e de formação que se vale de videogravação de ações de um ou mais sujeitos, numa dada situação, visando a posterior auto-análise delas. Em sua especificidade, a autoscopia supõe dois momentos essenciais: a videogravação propriamente dita da situação a ser analisada e as sessões de análise e reflexão.

Pela videogravação busca-se apreender as ações do ator (ou atores), o cenário e a trama que compõem a situação. As sessões de análise ocorrem a posteriori da ação e destinamse a suscitar e apreender o processo reflexivo do ator (ou atores) por meio de suas verbalizações durante a análise das cenas videogravadas.

Com pequenas diferenças e muitas aproximações, as autoras deste artigo utilizaram a autoscopia como principal estratégia de coleta de dados em pesquisas na área de Psicologia Educacional. Em ambos os casos, descritos mais adiante, as videogravações foram realizadas em escolas, especialmente no ambiente de sala de aula, cujos protagonistas do processo foram os docentes. Sabe-se, contudo, que a aplicação da técnica pode ser viável para contextos profissionais diferentes do magistério, em que o feedback das ações e a reflexão sobre elas sejam princípios importantes.

Com o propósito de apresentar e discutir a autoscopia no panorama metodológico da pesquisa e da formação profissional em educação, busca-se fundamentar, neste artigo, o procedimento e abordar vantagens do seu uso, além de alguns limites e cuidados a serem considerados, apresentando brevemente as experiências das autoras com o procedimento. Finalmente, algumas considerações são tecidas sobre o potencial formativo-reflexivo da autoscopia.

\section{Fundamentação}

0 procedimento de autoscopia é encontrado em estudos como os de Linard (1974; 1980), Prax; Linard (1975), Nautre (1989), Rosado (1990; 1993) e Ferrés (1996), que detalharam a função de avaliação de si mesmo que a videogravação permite através da confrontação da imagem de si na tela. Allan (1986) utiliza o termo "microensino".

0 procedimento denominado de microensino é considerado por Cooper (1983) como um precursor da formação do professor baseada em competências. Eram filmados em vídeo os modelos de competência que se desejavam ensinar e as fitas eram, então, exibidas aos professores em formação.

Na técnica da autoscopia, o indivíduo se vê em ação, o que permite o retorno da imagem e do som, retorno da informação, possibilitando uma modificação da ação pela percepção de causas e efeitos (Linard, 1980).

A autoscopia pode ser utilizada tanto em situações de pesquisa como nas de aprendizagem e formação de diferentes profissionais. 0 sujeito é o próprio objeto de feedback visual, ao se deparar com a imagem de seu corpo, a apreensão, pela memória, de sua representação e aparência.

Para Rosado (1990), a videogravação é uma técnica que permite a construção de uma representação do real, como espaço, tempo, objetos, personagens, assim como de seus movimentos, suas ações e suas interações. Essa linguagem permite a consciência do real e possui componentes cognitivos e afetivos.

Adotando uma perspectiva interacionista, Rosado (1993) compreende que o sujeito que assiste às videogravações não é um mero telespectador, no sentido passivo do termo. Ele é ativo perante os elementos da recepção videográfica, aos quais atribui sentidos dentro do contexto em que a situação apresentada acontece. Há, portanto, uma atividade psicológica que é subjacente ao processo de recepção televisual. Nessa atividade, o sujeito 
ressignifica os elementos apresentados, interpretando conteúdos e estabelecendo arranjos particulares, procedendo a articulações e atribuindo certos valores aos elementos, conforme sua bagagem pessoal de experiências e conhecimentos anteriores (p. 31).

Ao levar em conta a interação entre as videogravações e o sujeito telespectador ativo, ele próprio protagonista de cenas videogravadas, a técnica da autoscopia considera a imagem projetada na tela como categoria intermediária entre o aspecto exterior objetivo e a visão interna subjetiva, não pretendendo senão ocupar-se dos produtos que resultam dessa interação (Linard,1980, p. 8). Isso significa que o interesse consiste, sobretudo, na análise que o sujeito realiza, ao confrontar-se com a imagem de si na tela. É isso que Ferrés (1996) designa por vídeoespelho, com o sentido de o vídeo potencializar a função de auto-avaliação.

A função auto-avaliadora contida no procedimento implica contemplação e conseqüente reflexão sobre o próprio comportamento. A propósito disso, o autor lembra Auguste Comte, que rejeitava a introspecção, argumentando que não se pode observar algo ao mesmo tempo na rua e na janela. Comenta o autor que, a partir do desenvolvimento da tecnologia de vídeo, esta objeção de Comte já não faz mais qualquer sentido.

A palavra "vídeo", segundo Ferrés, provém do latim, do verbo videre, que quer dizer "eu vejo". Segundo ele, o vídeo é como um espelho, porém mais poderoso, pois:

0 espelho devolve à pessoa sua imagem invertida. 0 vídeo não. No espelho, a pessoa pode se olhar nos olhos. No vídeo não. 0 espelho impõe um único ponto de vista. No vídeo, a pessoa pode contemplar-se a partir de infinitos pontos de vista. (...) no vídeo vejo-me como sou visto, descubro como os outros me vêem. Vejo-me para me compreender. 0 fato de ver-me e de escutar-me leva a uma tomada de consciência de mim mesmo, de minha imagem, do som da minha voz, da qualidade e da quantidade de meus gestos, de minhas atitudes, de minha postura, de minha maneira de atuar e de ser. (1996, p. 52)

Por tudo isto, o funcionamento de uma análise através do recurso do vídeo não é tarefa fácil para se realizar. Ela envolve um processo de tomada de consciência e reflexão simultânea de variados códigos expressivos: linguagem, metalinguagem, deslocamentos, posturas, expressões faciais, maneirismos, entre outros, tanto de si como das demais pessoas envolvidas na situação registrada.

0 encontro objetivado consigo, por meio do vídeo, torna-se um instrumento para provocar verbalizações mediante o conflito que se instala entre a imagem e o eu subjetivo e mediante a possibilidade de promover articulações entre elementos envolvidos nos registros. Nesse encontro consigo, a pessoa se descobre e se comenta, olha a si como se olhasse a outro, permitindo-se fixar o olhar (Ferrés, 1996). É esse confronto que, paradoxalmente, ajuda a re-instalar o sujeito com todo o seu potencial reflexivo e expressivo.

Com efeito, Linard aproxima-se desta constatação, afirmando:

Ora, a imagem de si pelo vídeo é certamente o lugar por excelência das defasagens e conflitos (...); entre gestos e palavras, entre percepções externas e projetos internos, entre contrastes "após” e intenções “antes”, entre "eu" e "os outros", entre "aqui-agora" e "acolá, outrora, mais tarde”. (1980, p. 17 [tradução das autoras])

\section{E acrescenta:}

Pelo aspecto da representação de si na tela, conservada sob a forma de traço repetível sobre uma fita, esta imagem intermediária entre objetivo e subjetivo, é certamente também um lugar privilegiado de articulação entre experiência individual, consciente e inconsciente, e 
experiência social, presente e passada. (1980, loc. cit. [tradução das autoras])

Trata-se, pois, de uma reapropriação de si e também de uma ocasião privilegiada de autocrítica em face da representação que se tem do próprio papel no mundo e a atuação que nele se verifica.

\section{Algumas vantagens no uso do procedimento autoscópico}

A gravação em vídeo é uma forma de registro da imagem que conserva algo que já é passado; assim, a videogravação pode restituir o presente "como presença de fato, pois nele a exibição da imagem pode se dar de forma com a sua própria enunciação" (Machado, 1988, p. 67). A imagem gravada, portanto, prolonga a sua existência no curso do tempo (Zuzunegui, 1992).

Além disso, a tecnologia de videogravação é bastante adequada para o registro e investigação de fenômenos nos quais intervém o movimento (Ferrés, 1996). Fenômenos complexos formados pela interferência de múltiplas variáveis, muitas das quais atuam simultaneamente, como a prática pedagógica, por exemplo, são carregados de vivacidade e dinamismo. Para serem mais bem compreendidos, necessitam de uma metodologia capaz de conservar essas características. Desse modo, a videogravação permite registrar, até mesmo, acontecimentos fugazes e não-repetíveis que muito provavelmente escapariam a uma observação direta.

Outra particularidade contida nesse procedimento é a facilitação do distanciamento emotivo necessário para a análise reflexiva do material registrado. $\mathrm{Na}$ observação direta, a carga emotiva que acompanha a situação a ser registrada dificulta uma percepção mais isenta e profícua do fenômeno a ser compreendido. Graças a esse distanciamento, a tecnologia de videogravação carrega o potencial de transformar em novidade a ser conhecida muitas daquelas realidades do dia-a-dia, que parecem tão familiares aos sujeitos (Ferrés, 1996).
Na pesquisa autoscópica, os dados provêm das sessões de análise do material videogravado. Em face dessa particularidade, outra vantagem proporcionada pela tecnologia da videogravação é a versatilidade durante a exibição.

Rosado (1993) compara esta versatilidade com o "folhear de um livro", que permite ao leitor proceder a avanços, recuos, repetições, pausas. No vídeo, o material pode ser exibido em ritmo normal, acelerado, ou podendo contar, inclusive, com a possibilidade de congelar imagens ou repeti-las quantas vezes forem necessárias à boa apreensão. Toda essa versatilidade potencializa a possibilidade analítica, contribuindo para desentranhar os mecanismos subjacentes ao processo analisado. A técnica, então, coloca-se a serviço de necessidades que vão se configurando, ao longo do processo de análise, para os sujeitos envolvidos.

Analisando as vantagens da abordagem videográfica em pesquisas em sala de aula, Meira (1994) apontou que esta técnica permite construir uma "compreensão profunda sobre alguns casos significativos, ao invés de conclusões supostamente amplas" (p. 63), compreendidas apenas superficialmente por outras formas de abordagem.

Além de propiciar a amostragem do máximo de elementos possiveis que fazem parte de um fenômeno, a autoscopia oferece condições de análise crítica, permitindo exercitar uma intensa atividade intelectual. Rosado (1993) diz que, ao tentar entender e dotar de sentido o que lhe é apresentado, o sujeito apreende o objeto, percebendo aspectos que antes desconhecia, constatando contradições. E é esse processo reflexivo que o faz procurar novos conhecimentos. A confrontação, pela imagem, com as representações que se tem sobre si, já permite uma mudança de atitude. Por mais que não seja este o objetivo da utilização da autoscopia, que ela não tenha como meta a intervenção, só o fato de se ver na tela provoca, no indivíduo, possibilidades de modificações, a partir de vários pontos de vista. 


\section{Alguns limites e cuidados a serem considerados}

A imagem de si, no vídeo, não é inocente. Ela provoca manifestações nos indivíduos, especialmente naqueles que são mais resistentes a mudanças. A sua utilização deve ser cuidadosa, com a consciência de que ela pode causar até mesmo o desequilíbrio psíquico em indivíduos com personalidade patológica.

Além disso, seria ingenuidade assegurar que a câmera de vídeo, durante as gravações, apresente-se como um elemento neutro. Aqueles que fazem pesquisas em psicologia sabem bem que a simples presença do observador na sala de aula, por exemplo, já produz mudanças no ambiente pesquisado. Tem-se clareza, portanto, de que a câmera de vídeo realiza uma espécie de violação, porque penetra na intimidade, na privacidade do ser para depois entregálo novamente ao olhar. Contudo, a utilização do vídeo, segundo Meira (1994), tem a vantagem de registrar em detalhe as reações dos sujeitos investigados, possibilitando reconhecê-las e desconsiderá-las, se necessário.

Ao estudar os efeitos do feedback pelo vídeo sobre o processo ensino-aprendizagem em salas de aula, Linard (1974) concluiu que este retorno das informações, dos efeitos sobre as causas, é importante porque possibilita a todos os indivíduos envolvidos o conhecimento dos efeitos de seu próprio comportamento, e assim repará-los e corrigi-los, não só em relação às divergências de atitudes, mas também de normas, de motivações perante os companheiros envolvidos.

A preocupação com os efeitos do feedback, mais adiante, levou Prax e Linard (1975) a estudarem a relação entre as características de personalidade dos indivíduos em tela e a autoscopia. Concluíram que dependendo da estrutura de personalidade, o indivíduo se portava de diferentes maneiras, até mesmo diante da câmera de videogravação. Indivíduos maníacos, por exemplo, ficaram rindo, interrompendo a filmagem, fazendo mímicas. Fóbicos ten- diam a evitar que a lente captasse a sua imagem. Esquizofrênicos permaneceram numa atitude de imobilidade durante todo o tempo de filmagem.

Concluíram, também, que mesmo para os adultos considerados não-patológicos, a autoscopia gerava ansiedade quando o indivíduo se via em ação, no vídeo. Por isso, é esperado que durante o procedimento, apareçam atitudes elusivas, de não-identificação ou rejeição, como recusa em se rever, atitudes depressivas ou agressivas, atrasos ou ausências, partidas súbitas, entre outras manifestações defensivas por parte do sujeito.

Ferrés (1996) advertiu sobre duas atitudes contrapostas. De um lado, o sujeito autoscópico pode fascinar-se, evidenciando uma certa dose de narcisismo. De outro, poderá adotar mecanismos defensivos ou rejeitar-se em razão do impacto causado pela percepção da distância entre o eu-observado e o eu-idealizado. Geralmente, nessa situação, observam-se maneirismos e gestos de recomposição na pessoa.

$\mathrm{Na}$ área da formação profissional de professores, objetivando apanhar a evolução de estagiários de magistério para melhorar a perspicácia e objetividade de análise, Nautre (1989) encontrou outros problemas na utilização da técnica, que devem ser observados para que se possam evitá-los:

- o risco da "análise superficial”, ou seja, o indivíduo pode fazer uma análise muito pouco profunda, não parando a fita nos pontos críticos e não permitindo uma discussão destes aspectos, a não ser de modo superficial; - o risco da "ferramenta falha", ou seja, o sujeito pode fazer uma análise implementada sobre ferramentas conceituais tão complexas que necessitam de uma parada para explicação, por parte do próprio indivíduo, ou pelo docente que o acompanha;

- o risco do "ponto de vista negativo", quando o estagiário tem necessidade de que o professor o auxilie a revelar e a reforçar os pontos 
positivos de sua postura, atitudes, pensamentos, para que também possa considerá-los.

Apesar do exposto, deve-se considerar que a autoscopia também tem a vantagem de assinalar, por si mesma, seus próprios limites.

Por tudo isto, pode-se perceber que, na autoscopia, a imagem funciona como uma dobradiça que articula, ao seio do sujeito, os elementos do seu mundo real com o seu mundo imaginário, suas vivências pessoais, suas motivações, atenções e conhecimentos (Rosado, 1990). Para Ferrés (1996), a autoscopia permite "o encontro consigo mesmo, o encontro com o próprio corpo e, por intermédio dele, com a personalidade como um todo. Um encontro que é requisito indispensável para a tarefa da transformação" (p. 54). E, para Nautre (1989), a "autoscopia permite uma tomada de consciência na busca de uma melhor consciência de si e do fenômeno do grupo" (p. 29).

Em razão de seus limites, Linard (1980) recomendou que o procedimento seja utilizado com pessoas adultas e responsáveis, que considerem a autoscopia "bem-vinda" e se mostrem cientes de seus problemas.

\section{Duas pesquisas com fundamento austocópico}

\section{Pesquisando as relações entre as crenças e as ações da professora Letícia}

Uma das autoras utilizou a autoscopia com o objetivo de identificar, descrever e analisar as crenças de uma professora (Letícia) a respeito de sua sala de aula, bem como discutir as possíveis relações entre o pensamento e a ação docente. Foram realizadas, no decorrer do segundo semestre de um ano letivo escolar, sete sessões de filmagem e, em seguida, sete de discussão.

Letícia afirmou que no início do procedimento de coleta de dados ficava um pouco ansiosa por participar da pesquisa, tendo, inclusive, dificuldades para dormir na véspera da filmagem. Entretanto, depois do terceiro encontro, ficou mais tranqüila, pois percebeu que "podia dar conta" do que a pesquisadora lhe solicitava, ou seja, falar sobre o que estava vendo. Considerou que o conteúdo filmado constituía "uma boa amostra de como a classe funcionava e que as suas quartas-feiras começaram a render mais, porque os alunos sabiam que seriam filmados e voltavam logo do recreio e começavam a trabalhar".

A partir do momento em que ficou decidido que a classe da professora Letícia é que seria videogravada, a pesquisadora foi a até a sala e conversou com os alunos dizendo que faria um trabalho e que, para isso, precisaria filmar a classe durante alguns meses. De imediato as crianças reagiram animadamente, concordaram com a gravação e perguntaram se iriam “aparecer na televisão”. A pesquisadora informou-lhes que o filme só poderia ser visto na "TV da escola" e que se quisessem, poderia ser combinado um dia para assistirem a ele, juntos, o que acabou acontecendo após a coleta de dados.

Detalhando o procedimento realizado, deve-se informar que, às quartas-feiras, ${ }^{1}$ a pesquisadora realizava uma videogravação da sala de aula (das relações professora e aluno, professora e grupo-classe, professora e alunos, aluno e aluno, aluno e classe), durante aproximadamente uma hora e meia. As sete sessões de filmagem foram planejadas para acontecer após o horário do recreio, tentando, com isso, evitar as situações iniciais de correção de lição e organização do dia. 0 material videogravado não focalizava obrigatoriamente a professora, e foram buscadas as mais variadas situações curriculares e interacionais.

Em um outro dia da semana, às sextasfeiras, realizavam-se as sessões de discussão, quando o material filmado era exibido à professora e os episódios para sua análise eram seleci-

1. Este dia da semana foi escolhido em comum acordo entre a professora e a pesquisadora, considerando as disponibilidades de tempo de ambas e, também, por ser este um dia em que as crianças não saíam da classe para aulas de Educação Física ou Artística. 
onados por ela. Esta seleção dependia de alguns critérios que nem sempre foram explicitados por Letícia. Ocorreram situações, por exemplo, em que as cenas eram muito extensas e a professora afirmava que não apresentavam conteúdos relevantes para o objetivo do trabalho, ou as crianças estavam realizando uma atividade em silêncio (cópia, por exemplo) sem haver comunicação. Outras vezes, a classe toda estava trabalhando individualmente na produção de algum material solicitado pela professora (tais como relatos de atividades) e pouco ou nada falavam com os colegas ou com a docente, e nestas ocasiões, Letícia dizia que a pesquisadora podia "correr a fita” para que outras cenas fossem vistas.

Foram, portanto, selecionados pela própria docente, os registros em que apareciam situações mais motivadoras para sua fala, e por não ser esta seleção o objetivo do trabalho, Letícia não foi questionada a respeito dos critérios utilizados em sua escolha.

Após a apresentação das cenas ininterruptamente (sem seleção prévia por parte da pesquisadora), solicitava-se à professora que se manifestasse sobre o que considerara importante a respeito do material filmado. Em alguns momentos, a docente apenas descrevia o que estava ocorrendo e, em outros, analisava a ocorrência, acrescentando relatos de episódios que não estavam na videogravação. Por exemplo, referiu-se a um material coletado por um aluno no recipiente para lixo reciclado e relatou o que ocorrera antes e depois de ele pegar os papéis.

Nas sessões de discussão, a pesquisadora limitava-se a questionar a professora sobre as ocorrências videogravadas com perguntas do tipo "O que está ocorrendo?" ou "O que é que você me diz?”, ou, então, solicitava que a docente tecesse considerações sobre a dinâmica de um grupo de alunos. Em alguns momentos também, pedia maiores explicações sobre falas pouco compreensíveis. No início do procedimento de coleta de dados, a pesquisadora informou a docente de que o importante seria sua fala a respeito de sua sala de aula, não havendo cer- to ou errado nas suas verbalizações. Isto deve ter dado à professora um pouco mais de tranqüilidade para falar, dado que não seria, de forma alguma, censurada pela pesquisadora.

É interessante observar que já no primeiro dia de filmagem houve uma alteração na dinâmica da sala de aula como um todo, o que já era esperado. A professora, por exemplo, informou, na entrevista final, que as crianças estavam "mais santas" do que normalmente eram. Com o passar do tempo, os alunos foram se acostumando com a câmera voltada para eles, até mesmo "se esquecendo" dela em vários momentos. No início, alguns alunos solicitavam que fossem filmados, eles mesmos ou as suas tarefas escolares, e a pesquisadora os atendia. Houve, também, uma ocasião em que eles quiseram filmar, olhando por trás da câmera, e se organizaram para que todos pudessem fazêlo. Estas ações acabaram por aproximar a pesquisadora do grupo, possibilitando menor interferência na dinâmica da sala de aula durante as filmagens.

A autora conclui o estudo afirmando que esse procedimento de coleta de dados foi considerado bastante profícuo. Falando especificamente sobre as sessões de filmagem, Letícia revelou que, apesar da ansiedade inicial, havia gostado muito de assistir ao funcionamento de sua classe, como eram as relações entre as crianças, como elas se comportavam e como ela agia com os alunos e, mais ainda, que, apenas a partir das videogravações, pode conscientizar-se de algumas "coisas que precisariam mudar e onde devo puxar mais nas matérias. Devia ter isso todo ano!”.

\section{Pesquisando a relação entre psicologia e prática pedagógica no processo reflexivo da professora Gil}

A outra pesquisadora também encontrou na autoscopia um procedimento adequado para investigar articulações entre os conhecimentos de psicologia portados por uma pro- 
fessora (Gil) e a sua prática pedagógica, partindo do acompanhamento ao processo reflexivo sobre suas ações.

Após a adesão da professora Gil, num encontro preliminar, discutiu-se a melhor forma para que os alunos se acostumassem com a presença da pesquisadora em classe. Julgavase importante introduzir a câmera com o mínimo de interferência possível. A opção foi a de tentar garantir, inicialmente, a aceitação da pesquisadora pelos alunos.

Por isso, num primeiro momento, a câmera de filmagens não foi levada. Adotou-se um comportamento à semelhança de um auxiliar de classe, pois dessa forma, a nosso ver, a integração com os alunos seria favorecida. Definiu-se também que as videogravações seriam realizadas nas turmas da manhã, o que se deu de acordo com o horário das aulas de Ciências naquele turno. ${ }^{2}$

A estratégia planejada para as primeiras interações mostrou-se eficaz para preservar a naturalidade e espontaneidade do processo ensino-aprendizagem. Bastaram quatro dias letivos (correspondentes a vinte aulas) para introduzir gradativamente a câmera para o registro das atividades e interações entre professora e alunos. Isto ocorreu à medida que se identificavam manifestações concretas dos alunos de que a presença da pesquisadora estava incorporada. Registrou-se no Diário de Campo algumas situações a respeito:

“Cheguei cedo. Desde a entrada há alunos que já me reconhecem e me cumprimentam. (...) Com o sinal, fomos para a sala. (...) $\mathrm{Na} 7^{\circ}$ $\mathrm{A}$, a professora organizou os alunos em $\mathrm{du}$ plas, cada qual recebendo um texto diferenciado sobre elementos químicos e sua utilização na vida cotidiana. Nesse processo, as duplas interagiam entre si e houve momentos em que solicitavam a professora para esclarecer dúvidas. Enquanto a professora atendia uma dupla de alunos, outra dupla voltou-se para mim e perguntou 'o que é desinfecção?'. 0 texto que elas tinham falava a respeito do cloro. Sentei perto delas e perguntei se conheciam algum desinfetante e se sabiam para que era usado. Então, ficou esclarecido que a desinfecção é a eliminação de germes e que há cloro nos desinfetantes de banheiro, na água tratada e em produtos de limpeza em geral. As meninas lembraram da Kboa [marca de uma água sanitária] e da recomendação de colocar Kboa na água por causa do cólera (...).” (DC - 11/05/99)

"Não me sinto intrusa nas classes. (...) Os alunos estão bem naturais e não se alteraram com a presença da câmera. Apenas um ou outro fez acenos aos quais respondi, também, com acenos. (...) Como fomos para as ruas fazer a pesquisa na comunidade, na volta à escola desliguei o aparelho. Estava fazendo muito frio e, queixando-se dele, uma aluna enganchou no meu braço para ficar mais pertinho. Com o grupo de alunos, subimos a rua, conversando a respeito das impressões que tiveram nas entrevistas. Chegando na classe, todos sentamos. 0 garoto que se sentou ao meu lado ofereceu-me uma bala. Aceitei dizendo que guardaria para o intervalo. $\mathrm{Na}$ saída da classe, um grupinho de garotas que passava perto de mim perguntou sobre o perfume que eu estava usando. Dei atenção e elas chegaram até a 'me cheirar'. A professora, vendo a cena, comentou sorrindo: 'Viu, como já te aceitaram?'. Fiquei satisfeita porque me sinto à vontade com eles e eles se mostraram à vontade comigo." (DC - 20/05/99)

A primeira tentativa de videogravação ilustra dificuldades que um pesquisador encontra ao se propor a utilizar uma tecnologia mais sofisticada. 0 treinamento antecipado do manuseio

2. Uma das diferenças entre ambos os trabalhos refere-se ao objeto e a distribuição no tempo das videogravações. Enquanto na primeira pesquisa se fez o registro de uma única classe de $2^{a}$ série do ensino fundamental, uma vez por semana (quartas-feiras), na segunda registrou-se, de modo contínuo, 5 classes, sendo uma $6^{\text {a }}$ série, duas $7^{\text {as }}$ e duas $8^{\text {as }}$ séries do ensino fundamental, cada qual com aulas de cinqüenta minutos, seguindose os mesmos horários semanais da atuação da professora na disciplina de Ciências na escola. Deve-se considerar, ainda, que os alunos videogravados na primeira pesquisa, eram crianças, enquanto que os da segunda pesquisa eram adolescentes. 
da câmera, a leitura do manual de instruções e de um livro a respeito de videogravações não foram suficientes e a primeira experiência acabou frustrada. Note-se o registro no Diário de Campo:

"Fui para a escola de câmera em punho, tripé, fitas, bateria carregada. Escolhi a $8^{\text {a }} \mathrm{A}$ para iniciar o trabalho pois senti que os alunos estavam bem à vontade comigo. Cheguei à escola pouco antes do horário. $\mathrm{Na}$ sala, montei o equipamento e, com a entrada da turma, passei a registrar os acontecimentos. (...) à noite fui assistir, ansiosa, os registros que fizera. Que surpresa! Quase nada havia sido gravado. Perdi o trabalho daquele dia. Fiquei frustradíssima! No dia seguinte, chamei um técnico para descobrir o que fizera de errado. Apenas um botão fizera toda a diferença. Treinei com ele passo a passo, diversas vezes. Mais tarde liguei para Gil contando o acontecido. Ela me lembrou que na próxima quinta-feira haveria a mesma atividade com a $8^{\mathrm{a}} \mathrm{B}$. Combinamos de que eu estaria lá.” (DC - 18/05/99)

A partir da situação descrita, não houve maiores problemas com as filmagens que, embora amadoras, parecem ter cumprido a finalidade em vista.

O material coletado ocupou nove fitas de $8 \mathrm{~mm}$, cada qual com 120 minutos de duração. As fitas foram numeradas conforme os registros aconteciam. Houve ocasião em que o registro das atividades de um dia ocupou mais de uma fita. Nestes casos, codificou-se com letras para indicar que os registros pertenciam ao mesmo dia de filmagem.

Durante as filmagens, com a identificação de situações que se repetiam muito, ou que já se contava com material suficiente para ilustrá-las, ou ainda, que não se mostravam relevantes para a gravação, tendo em vista os objetivos da pesquisa, desligava-se a câmera. ${ }^{3}$

Para a primeira sessão de autoscopia com a professora, não se organizou previamente o material bruto coletado nas videogravações, realizando-a imediatamente após a filmagem.
Utilizou-se, apenas, o controle remoto do vídeo para parar a fita durante as verbalizações ou acelerar a imagem quando a professora não via pontos de interesse para discutir.

0 conteúdo verbal dessa primeira sessão, que foi gravado em áudio, transcrito e examinado, revelou alguns aspectos que levaram a optar pela modificação do procedimento. As falas da professora apresentavam-se excessivamente condensadas, sem evidências de contextualização ou retomadas das situações filmadas. Percebeu-se, então, que, em função da imediata realização da sessão, não estava presente para a professora a necessidade de evocar e descrever pormenores dos conteúdos das filmagens, uma vez que estes tratavam de acontecimentos recém-ocorridos e, por causa disso, boa parte deles não se convertia em dados verbalizados. Também, em virtude da ocorrência imediata da autoscopia, não se antecipou qualquer análise e reflexão dos conteúdos da filmagem, de modo que as verbalizações da professora ficaram à mercê da espontaneidade das situações, havendo dificuldades de garantir que muitos aspectos importantes da prática pedagógica fossem contemplados.

A partir dessas constatações, optou-se por realizar as videogravações e editar unidades de sentido contidas no material video-gravado, agrupando-as em diferentes conjuntos de acordo com a variabilidade de situações registradas. Para isso, cada fita foi analisada pela pesquisadora e submetida a uma pré-edição para organizá-la em termos de tipos de cenas, número de cenas gravadas em cada fita, turmas e séries onde ocorreram, descrevendo-as sucintamente. Também se registraram dados para reconhecer o início e a finalização de cada cena, ${ }^{4}$ e para situar e explorar aspectos a serem observados durante a autoscopia.

3. Como exemplos dessas situações tem-se: o momento da chamada nominal dos alunos; a entrada de um funcionário da escola para passar um recado à turma; a distribuição de carteirinhas nos horários próximos à saída da escola.

4. Isto foi necessário porque a pesquisadora não contou com uma ilha de edição apropriada, que permitisse regular o início e o final das cenas através de minutagem. 
Todas as cenas contidas em cada fita foram elencadas, o que permitiu identificar componentes importantes da prática pedagógica da professora e classificar tipos de atividades ou interações registrados no material bruto.

A partir da escolha das cenas pelo processo de pré-edição, passou-se a edições definitivas, eliminando imagens que não se correlacionavam com os objetivos do trabalho e juntando cenas correspondentes ao mesmo tipo de componente pedagógico identificado (ainda que estes proviessem de diferentes turmas ou momentos), agrupando-as em novas fitas a serem apresentadas à professora. Para todo este processo havia uma questão orientadora: "Que tipo(s) de componente(s) pedagógico(s) (atividades e/ou interações) aparecem no material registrado?". Das respostas a essa questão, formaramse três grandes blocos de edições:

- atividades escolares centradas na dinâmica da relação professor-aluno-conhecimento;

- atividades de avaliação da aprendizagem e da prática pedagógica;

- Interações que envolvem comportamentos e valores.

0 primeiro bloco foi composto de cenas com atividades planejadas ou antecipadas pela professora, ligadas diretamente à organização e efetivação do ensino de conteúdos. Neste bloco, constaram treze unidades de análise ou edições, conforme se segue:

- Rotinas de início de aula: pensamento ou curiosidade do dia; discussão e registro de pautas ou propostas de trabalho - nove cenas. - Exposição oral de conteúdos de ensino cinco cenas.

- Metodologias para compreensão e fixação de conteúdos: Gincana/bingo; jogos de regras/atividades em grupo - cinco cenas.

- Metodologias para compreensão e fixação de conteúdos: produções artísticas a partir do estudo de textos do livro didático/atividade grupal - cinco cenas.
- Metodologias para compreensão e fixação de conteúdos: leitura dirigida e comentada a partir de texto do livro didático - três cenas. - Metodologias para compreensão e fixação de conteúdos: resolução coletiva de questões problematizadas por duplas de alunos uma cena.

- Situações de feedback sobre conteúdos e organização do trabalho do aluno: individuais e coletivas - seis cenas.

- Leitura livre de revistas em disponibilidade - uma cena.

- Instruções para realização de trabalhos e tarefas grupais - duas cenas.

- Recursos materiais à disposição ou confeccionados em classe - três cenas

- Atividades em grupos - duas cenas.

- Atividades de revisão de conteúdos com apresentação de grupos ao coletivo da turma - três cenas.

- Resolução coletiva de exercícios com registro no quadro e esclarecimento de dúvidas três cenas.

O segundo bloco contemplou cinco edições formadas pelo agrupamento de cenas que envolveram atividades relacionadas com a avaliação da relação aluno-conhecimento e avaliação das mediações da professora. Note-se:

- Avaliação individual e parcial através de teste escrito - duas cenas.

- Explicações sobre a próxima avaliação com revisão das propostas e avaliações anteriores - uma cena.

- Assembléia de avaliação final do $2^{\circ}$ bimestre

- duas cenas.

- Explicações sobre como a nota é obtida a partir dos objetivos - uma cena.

- Correção da avaliação com acompanhamento do aluno e oportunidade de auto-avaliação e avaliação da disciplina - uma cena.

No terceiro bloco, agruparam-se cenas sob o critério de envolverem situações comportamentais não planejadas pela professora, mas 
que necessitaram do seu manejo ou, então, envolviam aprendizagem de valores. Neste bloco encontram-se cinco unidades de análise, conforme se segue:

- Professora sai da classe no horário de aula - uma cena.

- Alunos que não acompanham a atividade desenvolvida - três cenas.

- Situações envolvendo valores de responsabilidade para com o ambiente físico e humano - três cenas.

- O comportamento de Leandro - duas cenas.

- A rejeição de Liana pelo seu colega Muller - uma cena.

0 processo de edição, que resultou nas unidades de análise elencadas, foi conseqüência da decisão de recortar a realidade segundo significados e percepções que foram atribuídas às ações e interações videogravadas. Reafirmam-se, por isso, as constatações de Dessen (1995) acerca do envolvimento de vivências, conhecimentos, pressupostos teóricos e mesmo de hipóteses do pesquisador/observador no ato de editar, admitindo a possibilidade de que diferentes observadores notassem diferentes aspectos no material video-gravado e realizassem diferentes formas de edição. Como diz a autora,

o uso do vídeo não resolve os dilemas epistemológicos fundamentais, constituindo-se apenas em um recurso técnico, cujo modo de utilização independe dos procedimentos de recorte e análise de dados, os quais estão direta e intimamente ligados à postura teórico-epistemológica assumida pelo pesquisador. (p. 226)

Após o processo de edição, apresentouse o material à professora, solicitando-lhe que buscasse fundamentar sua prática pedagógica na psicologia da educação.

A apresentação das edições ao longo do desenvolvimento das sessões autoscópicas ocor- reu de acordo com o tamanho e o tempo de cada edição, e com a disponibilidade de horários da professora para sessões mais longas ou mais curtas. Por isso, houve ocasião em que uma sessão abarcou apenas uma edição, como houve sessões nas quais analisaram-se várias edições.

A cada sessão, tomava-se uma edição completa para ser analisada. Nessas ocasiões, Gil anotava e esquematizava, para si própria, observações e seqüências a serem descritas ou discutidas no momento de verbalização. Quando a pesquisadora perguntou acerca desse comportamento, Gil explicou que não gostaria de "perder nada" durante a verbalização. Devido ao dinamismo de muitas cenas, ela nem sempre conseguia captar tudo o que desejava, de modo que se repetia a edição no todo ou em partes, até que ficasse satisfeita e assinalasse que era possível iniciar as análises. Nesse processo, muitas vezes, ela fazia solicitações como: "Vá até aquele pedaço da fita e pare"; "Não consegui pegar tudo." "Dá para repetir aquele trecho?” Durante essas repetições Gil completava os tópicos de seu roteiro.

Portanto, houve retomadas e paradas da fita, a fim de melhor dar conta do objetivo proposto. Assim que a professora sinalizava que estava pronta para iniciar as análises, o gravador era ligado. Em todo o processo, ela mostrou-se atenta e meticulosa na sua tarefa. Ao final de uma das sessões, a professora confessou-se entusiasmada com o processo autoscópico, ressaltando as possibilidades analíticas do vídeo, as quais lhe permitiam estabelecer relações e focar elementos que no transcorrer das atividades em sala de aula ficavam imperceptíveis.

Durante as videogravações, observouse um pouco de ansiedade, logo superada pela professora. Durante as sessões, sua ansiedade parecia concentrar-se nos seus próprios registros, havendo, por vezes, expressões faciais ou manifestações verbais de aprovação, alegria, tristeza e até intensa autocrítica, de acordo com as cenas que lhe eram apresentadas. 


\section{Consideraçōes sobre o potencial formativo-reflexivo do procedimento}

Apesar de terem se utilizado da autoscopia como estratégia de coleta de dados em ambas as pesquisas, as autoras constataram no procedimento a possibilidade deste ser explorado na formação reflexiva de professores, no âmbito inicial ou na formação contínua.

Quando se centram os interesses em torno de idéias como professor reflexivo, prática reflexiva, acredita-se na importância do esforço dos formadores de professores em criar alternativas metodológicas que concretizem o discurso da profissionalização reflexiva.

Alguns estudiosos da formação de professores apontam nesta direção.

Nautre (1989) utilizou a autoscopia em cursos de formação de professores com o objetivo de oferecer uma reflexão sobre as práticas e uma visualização do comportamento dos alunos em formação. Tinha o intuito de visualizar as perspectivas de evolução do estagiário, permitindo aumentar a sua perspicácia e a objetividade de sua análise. Segundo essa autora, a utilização da autoscopia deve ser regida por uma escolha que inclua algumas razões:

- a qualidade e a precisão das tomadas permitem uma grande precisão de análise, o que aumenta consideravelmente a eficácia pedagógica da formação;

- a tela da televisão constitui um espaço operacional que participa desde a simulação até a possibilidade de adaptação de numerosos cenários. Assim, por meio deste procedimento, o indivíduo poderia assumir diferentes papéis, atuar em diferentes cenários de forma simulada, podendo analisar com mais cuidado o material produzido;

- a autoscopia permite a observação simultânea, na tela, das reações do grupo e dos atores em simulação, e, por fim, oferece um elemento de resolução ao problema de tempo, geralmente grande, nas situações de registro de comportamentos, ações e atitudes.

Quando Linard (1980) estudou a autoscopia na formação educacional e na formação no trabalho, ela verificou que além de registrar a imagem dos corpos e a voz dos indivíduos em atividade, esta técnica permite mais rapidamente o retorno não só dos comportamentos observáveis, mas, também, de sua aparência, sua auto-estima, sua história, assim como de seus desejos e, no sujeito, das representações psíquicas que ele tem de si mesmo e dos outros.

Considerou, também, que as ambivalências de sentimentos podem ser tidas como "o motor do ato de aprender" (p. 17). Elas existem, assim como as contradições, e são positivas. Através da autoscopia, fica claro que as dicotomias clássicas do gênero cognitivo/afetivo, desagradável/prazeroso, social/individual, são importantes e que não é necessário escolher um destes pólos em detrimento do outro.

Ainda no mesmo estudo, verificou que a autoscopia pode proporcionar um considerável enriquecimento à prática e à concepção de formação, uma vez que permite a reinstalação do sujeito com toda a sua totalidade subjetiva, racional e social, convidando-o a dispensar os modelos de aquisição de conhecimentos e comportamentos unicamente cognitivos e conscientes.

Graças à visualização imediata dos registros, a atividade de observação e autocorreção pode proporcionar um elemento dinâmico na evolução do indivíduo em formação. Não somente para ajudá-lo a corrigir seus desvios em relação aos eventuais modelos, mas, também, permite que se compare a outros dentro destes modelos e aprenda a se analisar e a se modificar diante de uma situação.

A autora ainda defende que a conservação dos comportamentos na situação permite uma análise do vivido, aproximando teoria e prática pelo movimento e avaliação constante entre as duas. Como um processo reflexivo, a autoscopia aparece como uma técnica que envolve tanto os formadores como os formandos, 
a instituição e o instituído, pois o sujeito é levado a situar-se em suas relações com os outros, com o saber e com o poder.

Dentro de um quadro mais notadamente terapêutico, a autoscopia pode contribuir para uma pedagogia do espaço transacional imaginário, entre o indivíduo e o mundo, permitindo-lhe avaliar cenários e personagens. (Linard, 1980, p. 20)

Um autor que pesquisou a partir do paradigma do pensamento do professor (Marcelo, 1987), afirma que a observação em vídeo dos elementos de ensino de outros professores ou de si mesmo pode ser um elemento eficaz para fazer com que os professores em formação reflitam sobre a complexidade do ato didático. Desse modo, referindo-se ao que denomina "estimulações de recordações”, este autor apresenta essa técnica como uma possibilidade de trazer à memória os processos e os pensamentos que ocorriam quando a conduta foi observada.

Allan (1986) - que utilizou o vídeo para auxiliar o ensino de inglês filmando, por exemplo, entrevistas simuladas com os alunos para que eles pudessem, posteriormente, observar-se falando percebeu que a vídeo-câmera lhes oferecia um instrumento de observação de suas próprias performances, além de dar-lhes a chance de se avaliar. Sua orientação é a de que cada sujeito assista e avalie a sua própria performance, uma vez que ninguém lucraria com a análise de outros indivíduos em treinamento.

Essa autora ainda sugere que a videogravação pode ser usada para que o docente observe como conduz a sua classe, que ele avalie as relações entre o que ele pensa e o ambiente de ensino em sala de aula, além de poder verificar como utiliza o tempo em classe passo a passo.

Mais recentemente, Guarnieri (1998) designou o procedimento pelo nome de coaching (treinamento/instrução), apresentando-o como metodologia de pesquisa e de formação de professores que implica a análise e reflexão conjunta de aulas gravadas ou registradas. Segundo ela, essa estratégia possiblita análises mais acuradas sobre o professor e seu trabalho permitindo informações sobre a relação pensar e agir na situação de ensino.

A autoscopia não é um elemento indispensável à formação, mas pode ser um “ajudante simpático" (Nautre, 1989, p. 6). A realidade do vivido é mais importante, sem dúvida, do que a imagem, mas esta técnica pode ser uma ferramenta auxiliar na reflexão sobre a prática vivenciada. Desse modo, a autoscopia não deve ser usada como um instrumento de controle em situações de formação de docentes, pois corre o risco de se criar um obstáculo intransponivel, o que acabaria prejudicando a própria técnica.

A autoscopia, sem dúvida, é um excelente instrumento de formação. No entanto, é vital que se tenha em mente a necessidade de reconhecer e devolver ao professor, enquanto sujeito autoscópico, a condição de sujeito de sua própria profissão, promovendo, portanto, além da avaliação de si, também a autonomia do seu pensar e fazer.

Para não incorrer numa postura meramente utilitarista, pragmatista, voltada simplesmente ao como fazer, será preciso que não se dispense a reflexão sobre o por que fazer, colocando em questão as finalidades educativas, sociais, políticas, éticas e humanas envolvidas no ato pedagógico.

Por mais sofisticada que seja essa técnica, ela não será suficiente se não houver qualidades profissionais e humanas dos responsáveis. Sem essas qualidades corre-se o risco de transformá-la em uma máquina de condicionamento ou em um "aborrecimento pedagógico" (Linard,1980, p. 21). 


\section{Referências bibliográficas}

ALLAN, M. Teaching english with video. Harlow-England: Longman Group Limited, 1986.

DESSEN, M. A. Tecnologia de vídeo: registro de interações sociais e cálculos de fidedignidade em estudos observacionais. Psicologia: Teoria e Pesquisa, Brasília, v. II, n. 3, p. 223-227, set./dez. 1995.

FERRÉS, J. Vídeo e educação. Porto Alegre: Artes Médicas, 1996.

GUARNIERI, R. M. A estratégia do "coaching" na pesquisa e na formação de professores. In: ENCONTRO NACIONAL DE DIDÁTICA E PRÁTICA DE ENSINO, 9., Águas de Lindóia. Anais... Águas de Lindóia, 1998. p.135 (Poster 28).

LINARD, M. Les effets du feedback par télévision sur le processus enseigner-apprendre en situation de groupes-classe. Bulletin de Psychologie, Tome XXVIII, n. 316 - spéciel, p. 9-12, 1974.

Autoscopie par video: l'image de soi au travail. Éducation Permanente, n. 52, p. 7-24, mars. 1980.

MACHADO, A. A arte do vídeo. São Paulo: Editora Brasiliense, 1988.

MARCELO, C. G. El pensamiento del profesor. Barcelona: Ediciones CEAC, 1987.

MEIRA, L. Análise microgenética e videografia: ferramentas de pesquisa em Psicologia Cognitiva. Temas em Psicologia, n. 3 , 1994.

NAUTRE, C. Etude sur l'utilisation de l'autoscopie video en formation permanente au Groupe Esc Lyon. In: CYCLE DE MANAGEMENT DES RESSOURCES HUMAINES À L'INSTITUT DE GESTION SOCIALE DE LYON, 3., Stage Février/Mars (Spéciel), Lyon, France, 1989, p.1- 41. (Mimeo)

PRAX, I.; LINARD, M. Autoscopie et personnalité. Bulletin de Psychologie, tome XXIX, n. 323, p. 704-715, 1975.

ROSADO, E. M. S. Communication mediatissé et processus d'evolution des representations - etude de cas: la representation de l'informatique. 1990. Thèse (Doctorat en Psychologie)- Université Lumiére Lyon, Lyon, 1990.

0 alcance do vídeo na sala de aulas. In: ROSADO, E.; ROMANO, M. C. J. de S. (Org.). 0 vídeo no campo da educação. ljuí, RS: Ed. Unijuí, 1993. p. 8-56.

ZUZUNEGUI, S. Pensar la imagen. Madri: Ediciones Cátedra, 1992.

Recebido em 14.04.04

Aprovado em 07.07.04

Ana Maria Falcão de Aragão Sadalla é professora doutora do Departamento de Psicologia Educacional da Faculdade de Educação da Unicamp.

Priscila Larocca é professora doutora do Departamento de Educação da Universidade Estadual de Ponta Grossa. 